\title{
THE EFFECT OF INSULIN, PITUITRIN AND ADRENALIN ON THE BLOOD-SUGAR LEVEL'
}

BY HARRY BLOTNER AND REGINALD FITZ

(From the Medical Clinic of the Peter Bent Brigham Hospital, Boston)

(Received for publication June 14, 1927)

\section{INTRODUCTION}

In 1913, Stenström (1) showed that simultaneous injections of pituitrin and adrenalin prevented the development of hyperglycemia obtained from adrenalin injections alone. In 1923, Burn (2) confirmed this observation and also showed that injections of the posterior lobe of the pituitary gland inhibited the hypoglycemic action of insulin. Stenström concluded that there was an antagonism between adrenalin and pituitrin, and Burn, that there was an antagonism between insulin and extract of the posterior lobe of the pituitary gland. It thus appears that the secretion of the pituitary gland may have a dual action in the regulation of the blood-sugar level, helping to prevent hyperglycemia on the one hand and hypoglycemia on the other.

In this paper are reported experiments which bear out Burn's conclusions in regard to the opposite effect on blood-sugar of pituitary extract and insulin. They perhaps may help to explain the cause of the antagonism noted by Stenström and Burn between pituitary extract and adrenalin.

\section{METHODS}

The experiments were made upon normal rabbits. The samples of blood were obtained from the heart by means of a syringe and fine needle. Determinations of the level of the blood-sugar concentration were made on $1 \mathrm{cc}$. blood samples according to the method of Folin and Wu (3), Lilly's Insulin, Parke, Davis and Co.'s Surgical Pituitrin and H. K. Mulford's Adrin (adrenalin solution 1:1000) were used

1 The expenses of this work were in part defrayed by the Proctor Fund of the Harvard Medical School for the Study of Chronic Diseases. 
throughout. Varying amounts of the drugs were injected in the marginal ear vein of the animals in the different experiments.

\section{RESULTS}

\section{The effect of insulin on the blood-sugar level}

So many data have been already reported in regard to the effect of insulin upon the blood-sugar concentration that it is needless to give more than a summary of our own observations. Convulsions from hypoglycemia were prevented by light amytal anesthesia. This
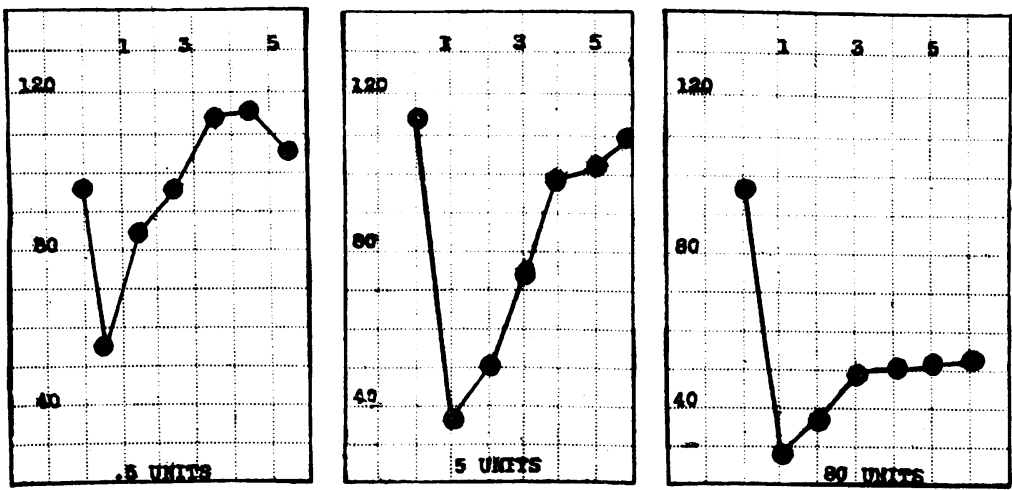

Fig. I. The Effect of Varying Doses of Insulin upon Blood-Sugar CONCENTRATION

The blood-sugar concentration is recorded in milligrams per $100 \mathrm{cc}$. of blood, the time interval in hours.

form of anesthesia was selected because, as first shown by Page (4), it has little or no influence on blood-sugar. The injection of insulin was invariably followed by a preliminary fall in the blood-sugar level and then by a secondary rise. This effect was obtained regardless of the amount injected: the chief difference in effect between a small dose and a large dose of insulin was that when large doses were given the resultant hypoglycemia lasted for a longer time than when small doses were employed. This fact is demonstrated by the bloodsugar curves from three typical experiments shown in figure $I$. 
The effect of pituitrin on the blood-sugar level

Burn showed that the injection of pituitary extract may be followed either by hyperglycemia or hypoglycemia. Our observations agree
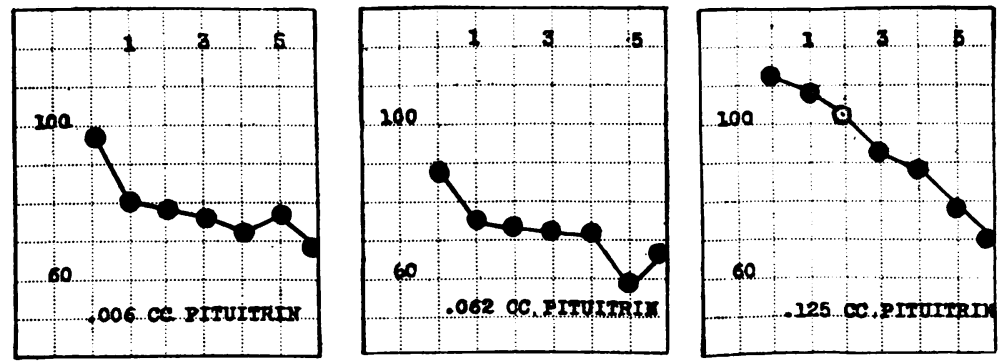

Fig. II. Hypoglycemia Produced by Varying Doses of Pituitrin

The blood-sugar concentration is recorded in milligrams per $100 \mathrm{cc}$. of blood, the time interval in hours.

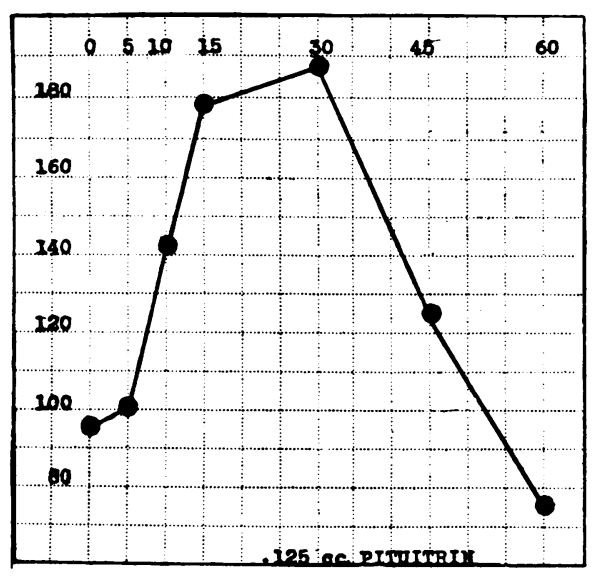

Fig. III. Hyperglycemia Produced by Pituitrin

The blood-sugar concentration is recorded in milligrams per $100 \mathrm{cc}$. of blood, the time interval in minutes.

with his. In certain of our pituitrin experiments the injection of the drug was followed by hyperglycemia and in others by hypoglycemia. Since we wish to emphasize particularly the production of hypo- 
glycemia after pituitrin injections, three curves illustrating this action are inserted in figure II.

In connection with these experiments, however, is one important feature which was perhaps not sufficiently stressed by Burn, but was emphasized by Stenström. The immediate effect of an intravenous injection of pituitrin, always, is to produce hyperglycemia. Such hyperglycemia may be transitory and may be overlooked unless blood samples are drawn at sufficiently frequent intervals after the drug is injected. In figure III is recorded a sugar curve to illustrate this point.
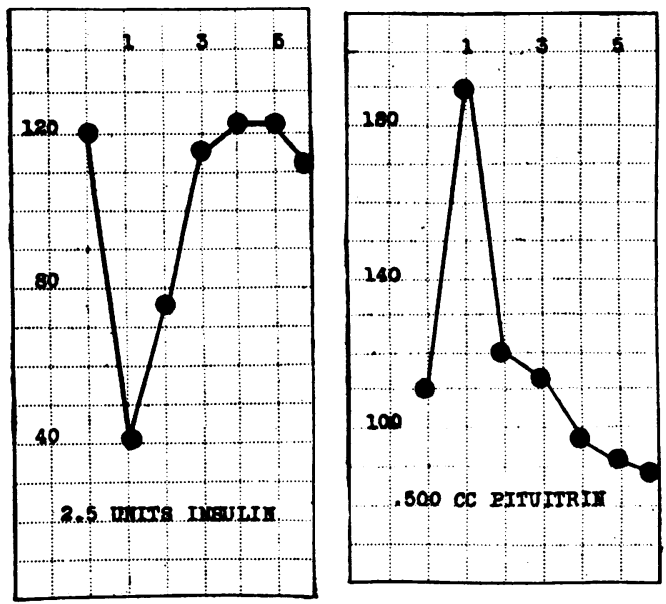

Fig. IV. A Comparison of Insulin and Pituitrin Blood-Sugar Curves

The blood-sugar concentration is recorded in milligrams per $100 \mathrm{cc}$. of blood, the time interval in hours.

In this experiment, had blood samples been drawn at hourly intervals instead of at more frequent intervals, the hyperglycemic effect of pituitrin would have been overlooked and the pituitrin injection would have been followed, seemingly, by a fall in the blood-sugar level.

We were impressed, as was Burn, by the apparently opposite effect of insulin and pituitrin. The injection of insulin was followed by a sharp fall in the blood-sugar concentration and a subsequent rise to normal: the injection of pituitrin was followed by a sharp rise in the 
blood-sugar concentration and a subsequent fall to normal or below: when properly graduated doses of the two drugs were given the resultant blood-sugar curves were almost directly the opposite of one another. A comparison of typical insulin and pituitrin blood-sugar curves is shown in figure IV.

\section{The effect of adrenalin on the blood-sugar level}

The effect of adrenalin upon blood-sugar concentration is as well known as that of insulin. The injection of adrenalin is followed by an
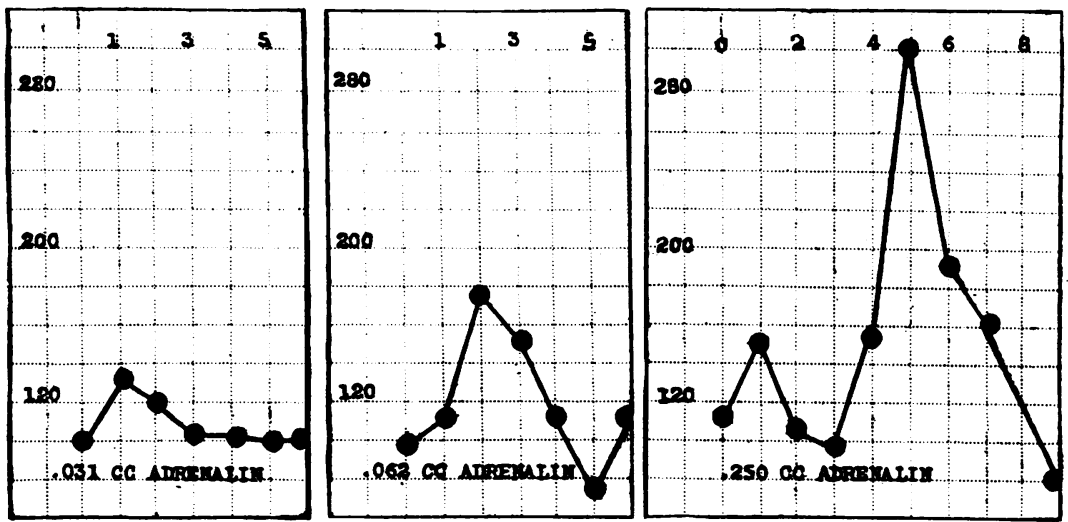

Fig. V. The Effect of Varying Doses of Adrenalin upon Blood-Sugar CONCENTRATION

The blood-sugar concentration is recorded in milligrams per $100 \mathrm{cc}$. of blood, the time interval in hours.

increased blood-sugar concentration and then by a gradual return toward normal. In our experience, however, the blood-sugar curves obtained with adrenalin were bizarre in contrast to those obtained with pituitrin, being less regular, and the curves being less strikingly the opposite to insulin than those obtained with pituitrin. Illustrative adrenalin curves are given in figure $\mathrm{V}$.

Adrenalin hyperglycemia, too, as pointed out by Stenström, usually lasted for a longer period of time than the hyperglycemia obtained with pituitrin and disappeared more gradually. In this way adrenalin hyperglycemia resembled the hyperglycemia produced from the 
intravenous injection of glucose and differed from that obtained with pituitrin. This difference between adrenalin and pituitrin hyperglycemia is shown in figure VI.

\section{Does pituitrin mobilize insulin?}

We wondered whether the relatively rapid fall in blood-sugar concentration so often observed after pituitrin injections could be due to the mobilization of insulin and to a different mechanism from

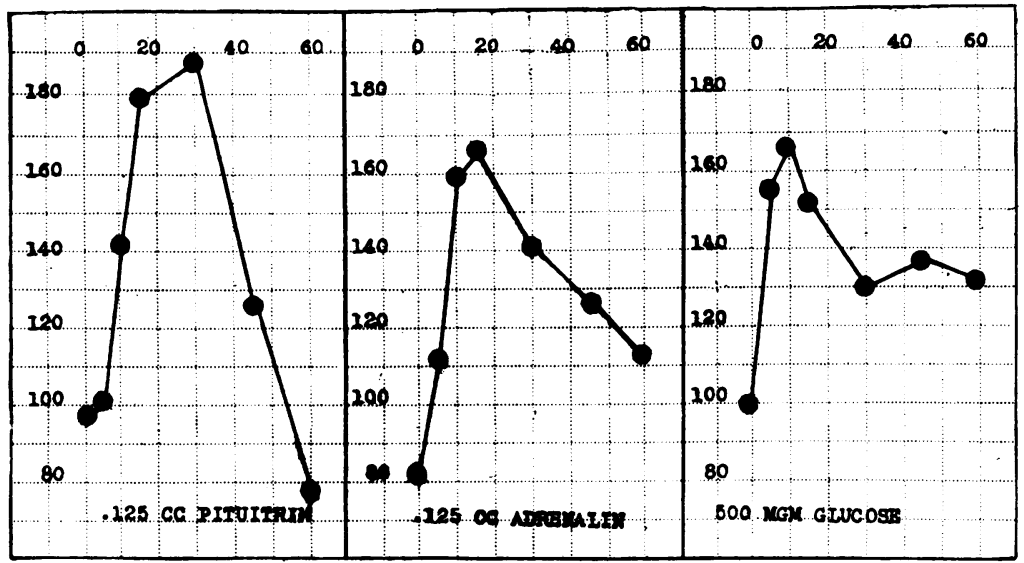

Fig. VI. A Comparison of the Rate of Disappearance of Hyperglycemia Produced by Pituitrin, Adrenalin and Glucose

The blood-sugar concentration is recorded in milligrams per $100 \mathrm{cc}$. of blood, the time interval in minutes.

that producing the more gradual and less regular fall in blood-sugar level after the injection of adrenalin.

We attempted to study this point by means of transfusion experiments. Twenty-five cubic centimeters of blood were removed from the heart of a normal animal, prevented from coagulating with sodium citrate, kept at body temperature in a water bath, and slowly injected into the ear vein of a second animal. Samples of blood from the recipient animal were withdrawn from the heart at intervals after the transfusion was completed and analyzed for sugar. It was possible to perform the transfusion on an animal under light amytal 
anesthesia without difficulty and about twenty minutes' time was taken to complete the injection. The result on the blood-sugar level of such a transfusion of normal blood is illustrated in figure VII.

As can be seen, the transfusion was followed by a slight rise in the blood-sugar concentration with a gradual return to normal.

An animal was injected with five units of insulin and fifteen minutes later $25 \mathrm{cc}$. of blood was withdrawn from the heart, this blood being injected into a second animal. We estimated that under these condi-

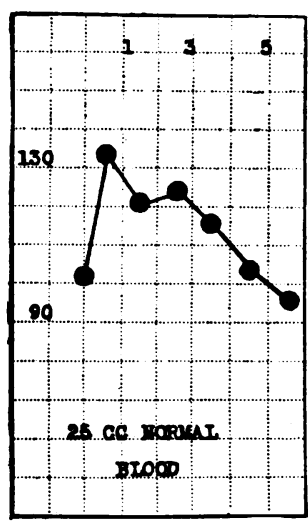

FIg. VII

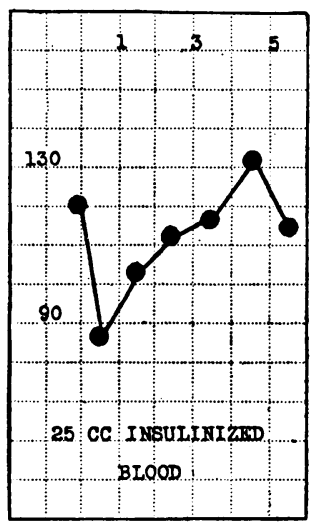

Fig. VIU

Fig. VII. The Effect of Transfused Normal Blood upon Blood-Sugar Concentration

The blood-sugar concentration is recorded in milligrams per $100 \mathrm{cc}$. of blood, the time interval in hours.

Fig. VIII. The Effect of Transfused "Insulinized" Blood upon BloodSugar Concentration

The blood-sugar concentration is recorded in milligrams per $100 \mathrm{cc}$. of blood, the time interval in hours.

tions such an amount of the donor's blood would contain approximately one half a unit of insulin-a quantity of insulin sufficient, as already demonstrated, to have an appreciable effect upon the bloodsugar level of a normal animal. The result of this experiment is illustrated in figure VIII.

There was a slight fall in the blood-sugar concentration as a result 
of this procedure followed by a gradual return to normal. The bloodsugar curve was like that obtained with a small dose of insulin and we are inclined to accept the finding as due to the insulin content of the transfused blood.

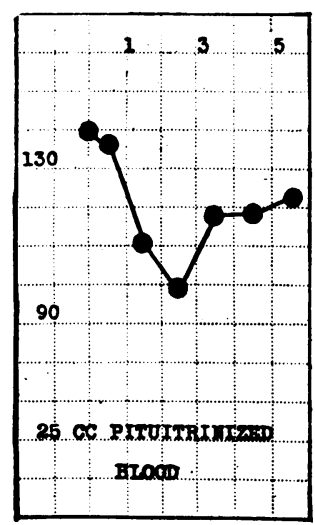

Fig. IX

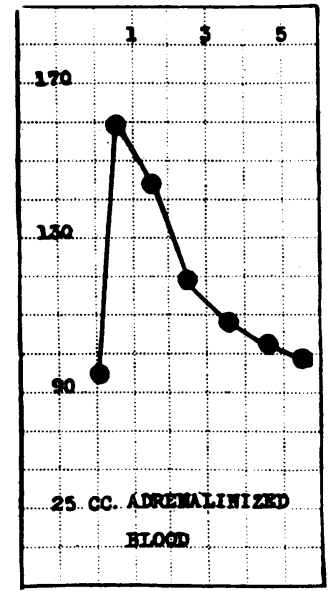

Fig. X

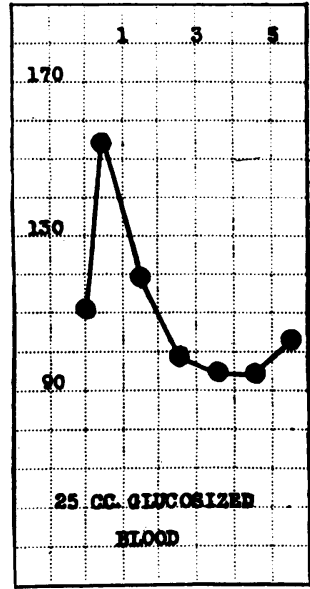

FIG. XI

Fig. IX. The Effect of Transfused "Pituitrinized" Blood upon BloodSugar Concentration

The blood-sugar concentration is recorded in milligrams per $100 \mathrm{cc}$. of blood, the time interval in hours.

Fig. X. The Effect of Transfused "Adrenalinized” Blood upon BloodSugar Concentration

The blood-sugar concentration is recorded in milligrams per $100 \mathrm{cc}$. of blood, the time interval in hours.

Fig. XI. The Effect of Transfused "Glucosized" Blood upon BloodSugar Concentration

The blood-sugar concentration is recorded in milligrams per $100 \mathrm{cc}$. of blood, the time interval in hours.

An animal was injected with $0.250 \mathrm{cc}$. of pituitrin solution and an hour and a half later $25 \mathrm{cc}$. of blood was withdrawn from the heart, and injected into a second animal. This time interval was allowed to elapse after the pituitrin injection and before the bleeding so that 
the blood would be obtained at a time when the blood-sugar level was falling toward normal from the peak of the pituitrin hyperglycemia, and at a time when we believed that if the reaction were due to insulin, its presence might be demonstrated by this method. The donor's blood-sugar level at the time of bleeding was 0.09 per cent. The result of this experiment is recorded in figure IX.

There was a slight fall in the blood-sugar concentration after the transfusion, followed by a gradual return to normal. The resultant curve was much like that obtained from a small dose of insulin and in the transfusion experiment with "insulinized" blood.

An animal was injected with $0.500 \mathrm{cc}$. of adrenalin solution and four hours later $25 \mathrm{cc}$. of blood was withdrawn from the heart and injected into a second animal. This time interval was allowed to elapse before the bleeding so that the blood would be obtained at a time when the blood-sugar level was falling toward normal from the peak of the adrenalin hyperglycemia and when the presence of insulin might be demonstrable if the falling blood-sugar value were due to this substance. In this experiment the donor's blood-sugar concentration at the time of bleeding was 0.10 per cent. The result of this experiment is recorded in figure $\mathrm{X}$.

Here there was a slight rise in the blood-sugar concentration after transfusion followed by a gradual return to normal. The resultant curve was like that obtained when normal blood was transfused and did not resemble that obtained with "insulinized" or "pituitrinized" blood.

Finally, an animal was injected with $750 \mathrm{mgm}$. of glucose and an hour and a half later $25 \mathrm{cc}$. of blood was withdrawn from the heart and injected into a second animal. This time interval was allowed to elapse before the bleeding so that the blood would be obtained at a time when the blood-sugar level was falling toward normal from the peak of the hyperglycemia so induced and when the presence of insulin might be detected if the falling blood-sugar value were due to this substance. In this experiment the donor's blood-sugar concentration at the time of bleeding was 0.10 per cent. The result of this experiment is recorded in figure $\mathrm{XI}$.

There was a slight rise in the blood sugar concentration after transfusion followed by a gradual return to normal. The resultant curve 
was like that obtained when normal or "adrenalinized" blood was transfused, and did not resemble that obtained with "insulinized" or "pituitrinized" blood.

It is a question of how much importance can be attached to these transfusion experiments on account of their artificiality. Certainly, the inference from them is that under the conditions stated the "pituitrinized" blood contained an appreciable amount of insulin and that the "adrenalinized" blood did not. The hyperglycemia produced by pituitrin seemed to disappear rapidly as the result of mobilization of insulin, while the hyperglycemia produced by adrenalin disappeared gradually and without the assistance of an appreciable amount of insulin. The results with "adrenalinized" and "glucosized" blood are at variance with the experiments of Zunz and La Barre (5) who were also interested in the possible stimulation of insulin by hyperglycemia of various sorts. Zunz and La Barre made transfusion experiments in dogs by anastomosis of the pancreatic vein of the donor to the jugular vein of the recipient animal. When the blood-sugar level of the donor was raised by injection of sugar or adrenalin into the saphenous vein, the blood-sugar level of the recipient animal diminished, a finding which they interpreted as due to a compensatory hyperinsulinemia.

If it is true as our experiments suggest, that pituitrin hyperglycemia mobilizes insulin to a greater extent than does adrenalin, this may explain Stenström's observation that extract from the posterior lobe of the pituitary gland when given simultaneously with adrenalin inhibits the development of adrenalin hyperglycemia. For, if the injection of pituitrin increases the available insulin in a comparatively short space of time, one might expect the longer continued hyperglycemia induced by adrenalin to be offset by such an insulin effect of pituitrin. The prompt initial hyperglycemia produced by pituitrin probably explains why insulin reactions can be immediately prevented by this substance.

\section{SUMMARY AND CONCLUSIONS}

This paper reports experiments in normal rabbits in regard to the effect of intravenous injections of insulin, pituitrin and adrenalin on the blood-sugar level. Insulin caused a fall in blood-sugar concen- 
tration followed by a rise to normal. Pituitrin and adrenalin caused a rise in blood-sugar concentration followed by a fall to normal or below normal. The blood-sugar curves obtained with insulin and pituitrin were almost directly the reverse of one another. Blood-sugar curves obtained with adrenalin were not so directly the reverse of those obtained with insulin and differed from those obtained with pituitrin in that the resultant hyperglycemia was of longer duration and subsided more gradually.

The rapid fall in blood-sugar concentration which developed following the injection of pituitrin appeared due to a recognizable increase in the circulating insulin, while the gradual fall in bloodsugar concentration which developed following the injection of adrenalin did not appear due to a significant increase in the circulating insulin. The basis for this conclusion lies in transfusion experiments. The injections of "insulinized" or "pituitrinized" blood in an animal was followed by slight hypoglycemia. The injection of normal blood, of "adrenalized" blood or of blood made hyperglycemic by glucose in an animaI was followed by slight hyperglycemia.

These experiments bear out the views of Burn in regard to the antagonism which exists between extract of the posterior lobe of the pituitary gland and insulin, and offer a possible explanation for the antagonism between pituitrin and adrenalin noted by Stenström.

\section{BIBLIOGRAPHY}

1. Stenström, T., Biochem. Ztschr., 1913, lviii, 472. Das Pituitrin und die Adrenalinhyperglykämie.

2. Burn, J. H., Jour. Physiol., 1923, lvii, 318. The Modification of the Action of Insulin by Pituitary Extract and Other Substances.

3. Folin, O., and Wu, H., Jour. Biol. Chem., 1920, xli, 367. A System of Blood Analysis. Supplement 1. A Simplified and Improved Method for Determination of Sugar.

4. Page, I. H., Jour. Lab. and Clin. Med., 1923, ix, 194. Isoamyl Ethyl Barbituric Acid. An Anesthetic Without Influence on Blood-Sugar Regulation.

5. Zunz, E., and La Barre, J., Compt. Rend. Soc. de Biol., 1927, xcvi, 710. Sur l'Augmentation de la Teneur en Insuline du Sang Veineux Pancréatique Après Injection d'Adrénaline. 